FWS : JHMC

$V-2$
DEPARTMENT OF COMMERCE BUREAU OF STANDARDS WASHINGTON, D. C.
Letter

Circular

IC 340

\title{
August I, 1932.
}

\section{SWEEPING COMPOUNDS (ALSO KNOWN AS "FLOOR SWEEP"}

(AND "DUST DOWN")

This letter circular has been prepared as a result of the numerous requests received by the Bureau of standar ds for general information regarding sweeping compounds.

Although there are many sweeping compounds on the market made of sawdust, sand, ground feldspar, oil, wax emulsions, coloring matter, disinfectant, etc., it is believed that in many cases fine sawdust moistened with water at the time of use will prove satisfactory. Some prefer a compound containing sand, oil, etc.; for example, the Treasury Department at one time used a compound made up according to the following formula:

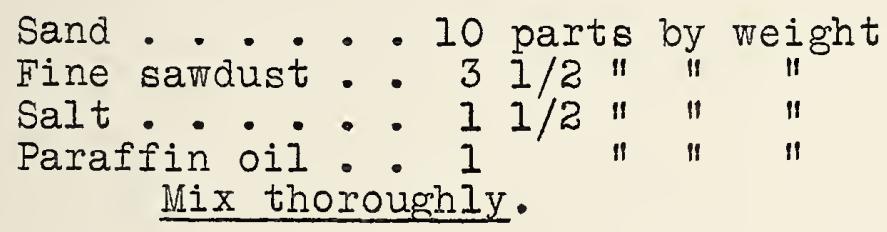

Certain Government offices have advisedus that a compound conforming to the following formula has been satisfactory in service:

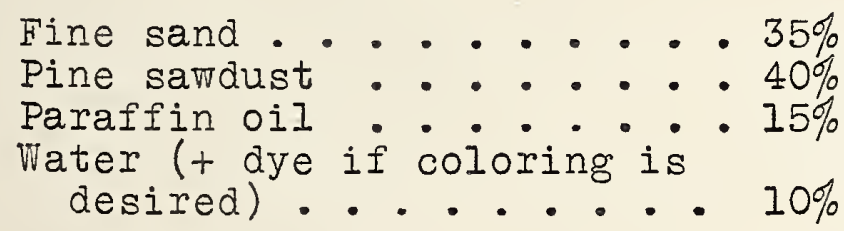

The Navy Department has used a compound consisting of a uniform mixture of clean, fine sand and finely ground sawdust properly impregnated with a refined heavy mineral oil and water. Such a compound must show on analysis: not more than 20 per cent of water, not more than 50 per cent of clean sand, not less than 5 per cent of refined heavy mineral oil, and the remainder finely ground sawdust. It is our understanding that the formulas 

IC 340, Sweeping Compounds - 2 .

mentioned are not patented. A copy of Navy Department Specification No. 51 ClO may be obtained from the Bureau of Supplics and Accounts, Navy Department, Washington, D. C. Some of the commercial compounds are colored with iron oxide or other pigment and contain naphthalene flakes. Wo aro unablo to advise, howcver, as to the merits of these compounds.

Essential oils, such as oil of eucalyptus, oil of sassafras, etc., are frequentiy added to impart a pleasant odor to the compound or to mask any unpleasant odor that may be due to the ingredients used. We have no data on all the disinfectants that might be used, except that a pine oil disinfectant is frequently used.

We are unable to furnish factory plans or data as to cost of materials or mixing machinery, etc. If made up in small lots the compounds could probably be mixed satisfactorily by hand. Information on mixing, packaging, and machinery that may be advantageously used can probably be obtained from the MacNair-Dorland Company, Inc., publishers of the trade journal "Soap", 136 Liberty Street, New York City. 


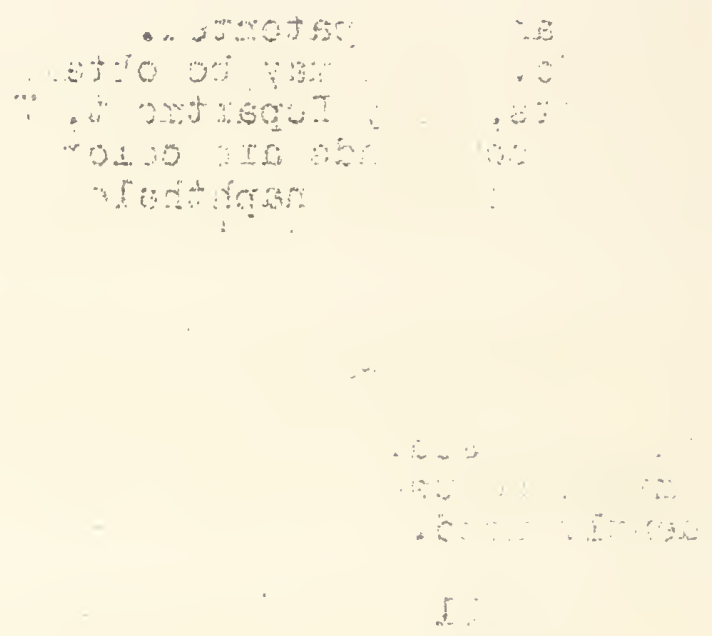

$1 \quad \cdot \cdots$ 

